infarction. Survival and Ventricular Enlargement Investigators. Circulation. 1997;96:827-33.

4. Liel-Cohen N, Guerrero JL, Otsuji Y, Handschumacher MD, Rudski LG, Hunziker PR, et al. Design of a new surgical approach for ventricular remodeling to relieve ischemic mitral regurgitation: insights from 3-dimensional echocardiography. Circulation. 2000;101:2756-63.

5. Hung J, Guerrero JL, Handschumacher MD, Supple G, Sullivan S,
Levine RA. Reverse ventricular remodeling reduces ischemic mitral regurgitation: echo-guided device application in the beating heart. Circulation. 2002;106:2594-600.

6. Guy TS 4th, Moainie SL, Gorman JH 3rd, Jackson BM, Plappert T, Enomoto Y, et al. Prevention of ischemic mitral regurgitation does not influence the outcome of remodeling after posterolateral myocardial infarction. J Am Coll Cardiol. 2004;43:377-83.

\title{
Robotically assisted repair of sinus venosus defect
}

Emile A. Bacha, MD, ${ }^{a}$ Gil Bolotin, MD, ${ }^{a}$ Karen Consilio, PA-C, ${ }^{\text {a } J a i ~ R a m a n, ~ M D, ~ a n d ~ D a v i d ~ G . ~ R u s c h h a u p t, ~ M D, ~}{ }^{\text {b }}$ Chicago, III

omputer-enhanced telemanipulation systems, also called robotic surgery, have recently emerged as a less-invasive option for a variety of cardiac surgical procedures. ${ }^{1}$ The advantages of the computerized robotic enhancement systems include ergonometric movements, 3-dimensional optics with tremor filtration and high-resolution video magnification, and wristlike articulations at the end of each instrument, providing intracardiac 7 degrees of freedom available at the tip of the instrument. This report describes the first documented use of a robotic surgical system for repair of a sinus venosus defect.

\section{Clinical Summary}

A 40-year-old man with a long smoking history presented with increasing fatigue. A sinus venosus defect was diagnosed. Cardiac catheterization showed a Qp/Qs of 2.4 with normal pulmonary artery pressures. The technique developed by Kypson, Nifong, and Chitwood $^{1}$ was used. In the operating room, a double-lumen endotracheal tube was inserted, and the patient was positioned supine, with his right chest elevated at $30^{\circ}$ and the right arm tucked on the side. After heparinization, the right femoral artery and vein were cannulated, and the inferior vena cava cannula was positioned below the diaphragm with transesophageal echocardiographic (TEE) guidance. A superior vena cava $17 \mathrm{~F}$ arterial cannula (Medtronic Bio-Medicus, Eden Prairie, Minn) was placed percutaneously through the right internal jugular vein under TEE guidance. A 3-cm right anterolateral minithoracotomy was performed, entering the fourth intercostal space. A rigid rib retractor was not used. During

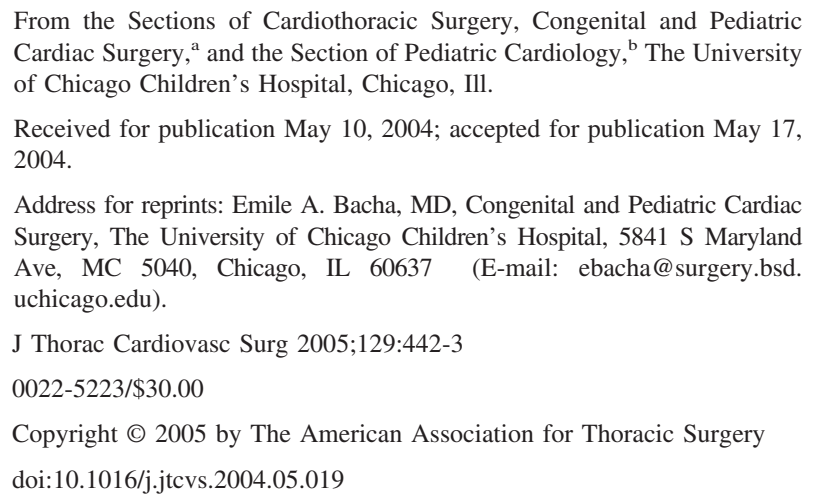

single-lung ventilation, the pericardium was opened, and a patch was harvested. The right-sided pulmonary venous drainage was inspected by using the $0^{\circ}$ endoscopic camera, and partial anomalous venous

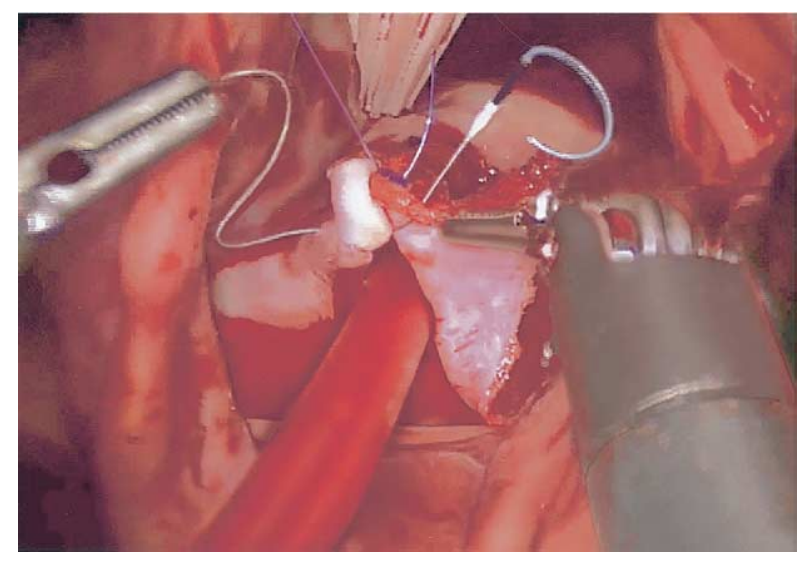

Figure 1. The first nitinol U-clip is being applied. The coil and its release mechanism (black and white portions of the clip) are clearly seen. A cardiotomy sucker is present in the left atrium and was introduced through the posterior aspect of the minithoracotomy.

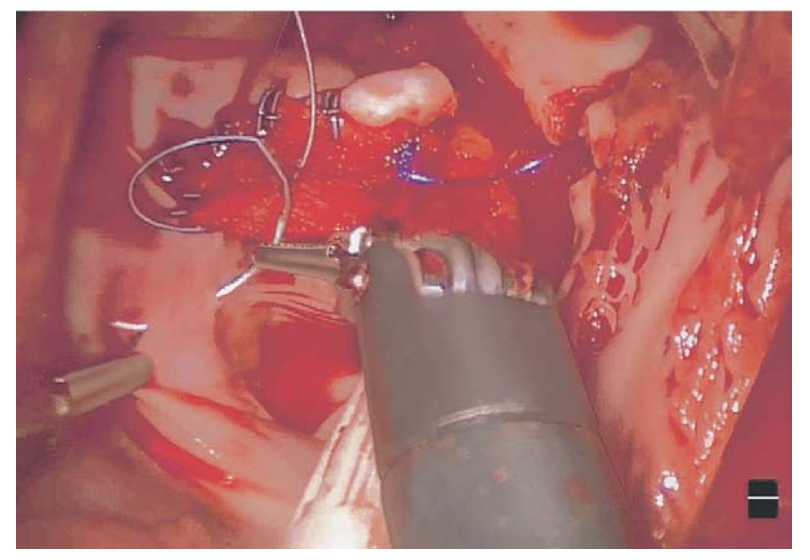

Figure 2. Several U-clips have been placed and released. The deployed coils are clearly visible. The limbus (superior aspect of the sinus venosus defect) is being grasped by the left robotic arm. 
return to the superior vena cava was excluded. A cardioplegia cannula was inserted into the ascending aorta with a 4-0 polypropelene pursestring suture. A 12-mm endoscopic trocar (Ethicon, Inc, Somerville, NJ) was placed into the pleural space through the minithoracotomy incision. The pleural space was insufflated with carbon dioxide to a maximum pressure of $8 \mathrm{~mm} \mathrm{Hg}$. Two additional 8-mm port incisions were made in the anterior axillary line at the third and sixth intercostal spaces. The Da Vinci Surgical Cart (Intuitive Surgical, Inc, Sunnyvale, Calif) was positioned at the operating table, and the left and right robotic arms were inserted into the thoracic cavity. A transthoracic aortic crossclamp (Scanlan International, Minneapolis, Minn) was inserted through an axillary stab wound and applied. ${ }^{1}$ Intermittent cold blood cardioplegia was used. Next the operating surgeon moved from the operating table to the surgeon's console. Pericardial stay sutures were placed on the posterior pericardial edge and exteriorized with crochet hooks. The inferior and superior vena cava were looped with tourniquets tightened from the outside. The right atrium was opened with the round-tip scissors, and stay sutures were placed. A floppy metal-tipped cardiotomy sucker was placed into the left atrium and exteriorized through the posterior aspect of the minithoracotomy. After identifying the usual landmarks, the sinus venosus defect was closed with a glutaraldehyde-treated pericardial patch sutured over the inferior portion with figure-of-8 sutures of 4-0 polypropylene and then over the superior-anterior aspect (limbus) with nitinol U-clips (size 90 and 105; Coalescent Surgical, Inc, Sunnyvale, Calif; Figures 1 and 2). The right atriotomy was closed with a running polypropylene suture, and after deairing, the crossclamp was released. The patient was separated from cardiopulmonary bypass with no difficulties. The crossclamp time and bypass times were 75 and 140 minutes, respectively. After decannulation, hemostasis, and chest tube placement, all incisions were closed. TEE confirmed a good repair. The patient was extubated immediately after arrival to the intensive care unit and was discharged to home on postoperative day 4. At 6 months' follow-up, he is asymptomatic.

\section{Discussion}

Robotic surgical systems are slowly being implemented in the repair of intracardiac congenital heart defects, such as secundum atrial septal defect closure or tricuspid valvuloplasty in adults. ${ }^{2-5}$ Potential benefits include less pain and a shorter postoperative recovery period. ${ }^{4}$

As in other robotic procedures, the myocardial ischemic time is clearly longer than would have been required during an open operation. However, the nitinol clips were being used for the first time and proved extremely advantageous by eliminating the need for intracorporeal tying. In future cases, these will be used exclusively to secure the patch.

Application of robotic techniques in pediatric cardiac surgery remains distant. The current 3-dimensional cameras require a 10to $12-\mathrm{mm}$ port, whereas instruments require at least $5-\mathrm{mm}$ ports. These would fill the pleural space of a less than $20-\mathrm{kg}$ child, and instrument conflicts would be frequent because the port sites should be separated by at least 4 to $6 \mathrm{~cm}$. In addition, peripheral cannulation of a small child is more complex because of the small size of the femoral vessels. However, given that exposure of right-sided cardiac structures is relatively simple, there is no reason why, provided future technologic advances in pediatric cannulation and perfusion technology, as well as robotic instrumentation, lesions such as a ventricular septal defect or an ostium primum defect cannot be repaired in children through a totally endoscopic approach.

\section{References}

1. Kypson AP, Nifong LW, Chitwood WR Jr. Robotic mitral valve surgery. Semin Thorac Cardiovasc Surg. 2003;15:121-9.

2. Argenziano M, Oz MC, Kohmoto T, et al. Totally endoscopic atrial septal defect repair with robotic assistance. Circulation. 2003;108: $191-4$.

3. Wimmer-Greinecker G, Dogan S, Aybek T, et al. Totally endoscopic atrial septal repair in adults with computer-enhanced telemanipulation. J Thorac Cardiovasc Surg. 2003;126:465-8.

4. Cannon JW, Howe RD, Dupont PE, Triedman JK, Marx GR, del Nido PJ. Application of robotics in congenital cardiac surgery. Semin Thorac Cardiovasc Surg Pediatr Card Surg Annu. 2003;6:72-83.

5. Autschbach R, Onnasch JF, Falk V, et al. The Leipzig experience with robotic valve surgery. J Card Surg. 2000;15:82-7. 